\title{
Teaching Students to Create rather than Demonstrate and Consume Knowledge: A Posthuman Perspective on Rhetorical I nvention and Teaching
}

\author{
Maureen Daly Goggin \\ Chair, Department of English \\ Arizona State University
}

The scholarship of teaching and learning (SOTL) calls for engaging students in the learning process and creating pedagogical environments that foster active learning. For me, such learning has an epistemological dimension whereby students should be taught and encouraged to create knowledge rather than merely to demonstrate and consume knowledge of issues and questions that already have known answers. Keith Trigwell and Suzanne Shalea (2004) propose a "practicebased concept of scholarly teaching" (p. 535) that resonates with my theoretical concept of active epistemological learning. Of their model they argue that:

In its descriptive aspect, surely a good conception of scholarship of teaching would accord proper priority to the idea that teaching is an activity that emerges in collaboration with students as partners in learning. In its purposive aspect, surely a good conception of scholarship of teaching would honour and publicly acknowledge the scholarly energy that is creating situations in which students learn, rather than a scholarly energy which creates situations in which teachers instruct. (p. 534)
Although creating situations within the classroom, whether face-to-face, hybrid, or online, that allow learning to take place is a critical strand of SoTL, the role of knowledge in relation to learning has received less attention. For example, Michael Prosser (2008) argues that the main point of SoTL is "to work towards improving our students' learning" (p. 4), but he has little to say about the epistemological dimension of that learning. Similarly, David Dees (2008)

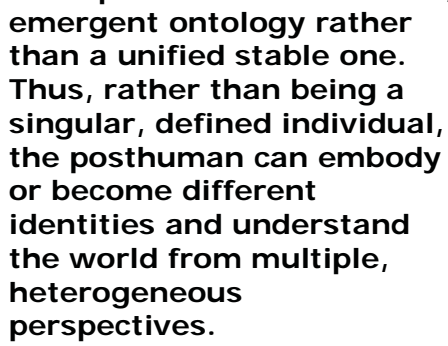
explains that "I have now committed myself

as an educator to create learning environments with my students, not for them... the SoTL project..served to free me as an educator, moving away from an instructor-driven perspective to a more learner-centered approach" (p. 3); but what he means by "learner-centered approach" is assumed rather than articulated. Thus, although notions of teaching as collaboration and engagement with students are running themes in much of the SoTL scholarship, few scholars have taken on the role of knowledge making as opposed to knowledge demonstration, a role that I take up here.

Since my field is rhetoric, I turn to rhetorical invention as a site for a model of teaching knowledge creation and in the process offer a reinvention of inventio. As the first canon of rhetoric, invention itself is a complicated, dynamic act with a long distinguished history, dating at least as far back as ancient Greece. As Richard Young and Yameng Liu (1994) point out, "modern reinvention of inventio has been a history of inquiries without an agreed-upon end of rhetoric, which has led to an ever richer copia of perspectives, theories, models and paradigms" ( $p . x i$ ). In other words, rhetorical invention is fluid and multiple, itself a source of ongoing debate. Thus, invention itself is the act of reinventing invention.

Here, I turn to a cultural posthuman perspective to explore this dynamic, fluid conceptualizing of invention with its history of competing inquiries that have 
hovered over and in time and place. A posthuman perspective on rhetorical invention raises questions such as: What does a posthuman perspective on rhetorical invention have to offer? How does it contribute to teaching and learning? And simply, how do we conceive of a posthuman perspective on rhetorical invention?

\section{Posthumanism and Rhetorical Invention}

Posthumanism, of course, is not a coherent, agreed-upon theoretical concept. It is a series of competing and contradictory views, so let me describe the theoretical construct I'm working with here. As Donna Haraway (1991) first theorized, posthuman practice is the ability of the human to easily shift perspectives and enact these through differing identities. That is, the posthuman has a fluid, emergent ontology rather than a unified stable one. Thus, rather than being a singular, defined individual, the posthuman can embody or become different identities and understand the world from multiple, heterogeneous perspectives. Extending Haraway's argument, N. Katherine Hayles (1999), whose own work is central to critical posthumanism, argues that in the late 20th and 21st centuries, liberal humanism-a perspective that splits mind and body, with body being just a placeholder for the mind-has been exploded under the influence of information technology that has called the mind/body connection into question. Within a posthuman perspective, the posthuman is understood as one who relies on context rather than relativity, on situated objectivity rather than universal objectivity, and on the creation of meaning through "play" between constructions of informational patterns. Shannon Bell (2005) thus points out that in comparison with liberal humanism, posthumanism "has a much stronger critical edge attempting to develop through enactment new understandings of the self and other, essence, consciousness, intelligence, reason, agency, intimacy, life, embodiment, identity and the body"-all critical aspects that are key to rhetorical invention.

To understand how this perspective frames theorizing of posthuman rhetorical invention in a manner different from other theories of invention, let me briefly describe some of the more common perspectives.

\section{$20^{\text {th }}$ Century I nvention}

Although now somewhat dated, Karen Lefevre's (1987) Invention as a Social Act offers one way of parsing these competing theories into four models that vary in their locus of knowledge and meaning. The first model is subjectivist. For the theories under this model, the locus of knowledge is the self; a writer looks inside him- or herself to identify knowledge, meaning, and truth. This perspective views rhetorical invention as a creative process, emphasizing a "generative subjectivity as the decisive factor in initiating and sustaining the writing process" (Young \& Liu, 1994, p. xi). The second model is objectivist. Knowledge resides in the stable world waiting to be uncovered, usually by means other than rhetoric. The theories under this model posit a belief "in a preexistent, objective determining rhetorical order whose grasp by the rhetoric holds the key to the success of any symbolic transaction" (Young \& Liu, 1994, p.xiii). The writer thus looks outside herself to find what she wants to say. Writing under this perspective is aepistemic and is concerned only with style and arrangement. LeFevre's (1987) third model, what she terms collaborative, holds that invention occurs by "interacting with people who allow developing ideas to resonate and who indirectly or directly support inventors. Listeners and readers receive and thus complete the act of invention" ( $p$. 52 ). Under this model, knowledge and meaning are co-constructed between two or more stable subjects. Invention rests on interaction among people. The fourth model LeFevre terms the collective. Under this perspective, knowledge and meaning rest with an all-powerful supracollective such that all humans are written. Invention, then, is primarily a hermeneutical act as agency is closed off. 
LeFevre (1987) sets up these categories of theoretical views as a continuum moving from the subjective individual to the social collective. Despite the divergent epistemologies of these models and the multiple theories under each, each depends on a particular model of subjectivity, either an independent, unified sovereign subject that writes or the binary opposite, a passive, dependent subject that is written. The inventing action in three of these models is unidirectional: from the self, the world, or from the supracollective to the self. That is, knowledge and meaning reside in the self, or in the world, or in the supracollective. The collaborative model grants knowledge and meaning in interaction among people, and does so in a bidirectional movement. However, this last model, like each of the others, is subjectcentric, relying on stable and unified active or passive subjects.

Like posthumanists, post-process theorists have challenged this notion of subjectivity as "unified" and "stable," separate from the context and spaces of writing. In terms of writing classes, Christopher Keller (2004) calls for us to "recognize student subjectivities as always on the move, always changing, and always shifting within, among, and between various locations and spaces" (p. 207). He argues that we need to theorize student writers as people traversing in "exile, displacement, immigration, migrancy, diaspora, or tourism" (p. 208). This concept of fluid, constant change is made most visible in cyber environments, in

the ways that students' identities are always in a state of constant flux because of their 'travels' and 'movements' through these cyberspaces where they are always interpreting and producing various forms of discourse from a variety of social, cultural, and political positions (Keller, 2004, p. 214),

as well as gendered, sexualized, and class positions. This new sense of subjectivities as fluid, moving, and changing, calls for new ways of thinking about invention, and what it is we ask students to do, and how we conceive of learning.

\section{Connectivity}

Recently, Steven Johnson (2010), the director of TEDTalks, has been exploring where "good ideas" come from, and he argues for a notion of connectivity that he calls "networks" for understanding the origin of good ideas. As he points out, much of our language connected to invention and good ideas limits our conception of these acts, and works against notions of connectivity. I deas are couched in terms of a "flash, a stroke, a eureka, an epiphany, a light bulb," all of which share a basic assumption that an idea is a single thing, something that happens in a wonderful, illuminated moment to an autonomous, independent agent. But, as he argues, this simply is not the case. Thus, we need to

The challenge for us as teachers is how to create environments or spaces for students that encourage idea production: that is, to create knowledge rather than merely demonstrate and consume knowledge. change our models of what deep thinking looks

like. He asserts it is more accurate to think of an idea as a new network firing inside the brain. Thus an idea is a new configuration. We see these networks in the intertextual traces that saturate our discourses. Yameng Liu's (2002) observation calls attention to these traces when he notes "what is 'new' is always already saturated with 'traces' of the old, what is 'unique' saturated with 'traces' of the common, what is 'different' saturated with traces of the same" (p. 60). In his words, to be inventive is to strive for the new without attempting a clean severance with the old and to search for the unique through an identification with the common; it is to try to achieve originality, with the understanding that the more original a perspective is, the more deeply it is rooted in the conventional. (p. 60) 
This perspective resonates with research findings by David Kaufer and Cheryl Geisler (1989) on authorial newness. Based on their scholarship on academic authorship, they offer four propositions about authorial newness:

1. Newness is less a property of ideas than a relationship between ideas and communities, and less an individual trait than a regularity of communal life and structure.

2. Authorial contributions are ... never new in the sense of 'brand new' or 'out of the blue.' They are carefully tied to and shown to grow out of existing knowledge.

3. When authors seek to contribute, they search for ideas that flow from existing knowledge and that promise to extend it. Synthesizing the literature they want a place in, authors lay the ground on which they hope to make their imprint. They manage to be new when the imprint they make fits the community standard, and when they can make it before their competitors have a chance to make theirs.

4. Newness turns on a delicate balance between the inertia of the past and the drive to change it. Contributions that respect the past with too little change become tired and predictable. . . . Conversely, contributions that push change with too little rootedness are likely to remain unclassifiable rather than revolutionary. (pp. 299-300)

Authorship is an emergent contribution to circulating discourses that are connected by fluid networks. I rene Clark (2005) notes that "originality in the academic world evolves from the voices of others" (p. 149).

The challenge for us as teachers is how to create environments or spaces for students that encourage idea production: that is, to create knowledge rather than merely demonstrate and consume knowledge. I argue we need to construct inquiry-based sites, or what Johnson calls "liquid networks," where different ideas collide and jostle and yield new notions and students learn how to enter these swirling spaces. This challenge requires a new theory of rhetorical inventio.

\section{Reinventing I nventio}

Here, I propose a theory of invention that is dynamic, multidirectional, and comprises multi-interactive snippets of processes that vary by the different social spheres the rhetor traverses; the differing social and political positionings allowed by the settings in which the rhetor operates; the differing oral, print, and digital discourses the rhetor engages; and the differing material objects the rhetor collides against; as well, a theory that accommodates the multiplicities of a given rhetor. Such a theory recognizes a fluid network rather than a sovereign writer as the site of creation. Debra Hawhee (2002) in "Kairotic Encounters," offers a view that opens up a space for this perspective. She argues for a concept of subjectivity and invention that she describes as "invention in the middle." For Hawhee, "inventionin-the-middle' assumes that rhetoric is a performance, a discursive-material-bodily temporal encounter, a force among forces" (p. 24). In her model, the subject is fluid-the outcome rather than the source of the rhetorical situation, fluidly acting in the moment to effect change. In her words, "One invents and is invented, one writes and is written, constitutes and is constituted" (p. 18). Hawhee's theory opens a space in which to reconceive of invention as operating, not from a single sovereign subject, but from the practices in which the rhetoric is formed and circulated in networks. Here, I extend Hawhee's invention in the middle.

I argue that we need a theory that recognizes the fleeting moments of any writer whose very being both writes and is written, who both ventures into the world and is constrained by it, who both investigates the self and is investigated by it, who both engages and is engaged by former discourses, who both connects and is connected with others. We need, as Kelly Pender (2011) points out in arguing to recoup a robust concept of techne, ${ }^{i}$ to offer 
a response to the either/or mentality-either we control language or we let it control us; either we use language to represent the world or we free it from representation; either we write for the sake of communication or we write for the sake of writing itself. (p. 152)

Such dichotomous views have "obscured the contradictory nature of writing as a productive art" as a techne (p. 152). That is, these binaries set up complicated problematics.

Of course, the relationship between binaries is richly complex, as Bruno Latour (2000) reminds us. He argues that conceiving of this relationship in simple dialectical terms is far too restrictive, challenging us to

abandon the mad idea that the subject is posed in its opposition to the object, for there are neither subjects nor objects, neither in the beginning-mythical-nor in the end-equally mythical. Circulations, runs, transfers, translations, displacements, crystallizations-there are many motions. (p. 10)

These motions take place in social circulations in which rhetors participate, e.g., social spaces, whether in private, public, or institutional places. Conceiving of rhetors in posthuman terms, Latour (2005) elsewhere points out that "we tend to limit the social to humans and modern societies, forgetting that the domain of social is much more extensive than that" (p. 6). Animals and plants are social, too. We need to refigure the human as not central to all else; we need to understand posthumans as in relation to all social entities. Most important are the sets of relations among social entities.

\section{Social Network Theory}

Social network theory is a move in this direction, viewing as it does social relationships in terms of nodes and ties. Nodes are the entities within a network, and ties are the all-important relationships or connections among them. Entities may be organizations, businesses, individuals, or other things and beings we don't think of as human. Such a view assumes, as Giles Deleuze and Félix Guattari (2008) argue, "the only way to get outside the dualisms is to be between, to pass between, the intermezzo" (p. 305). Passing in the intermezzo calls for dynamic theories of literacies that "suggest that becoming literate involves negotiating among competing discourses and cultures moment by moment, a perspective that foregrounds material conditions" (Shroeder 2004, p 61). Thus,

What was once seen as socialization

...we need a theory that recognizes the fleeting moments of any writer whose very being both writes and is written, who both ventures into the world and is constrained by it, who both investigates the self and is investigated by it, who both engages and is engaged by former discourses, who both connects and is connected with others.

into standard discourses, such as appropriating or being appropriated of Bartholomae's Inventing the University model, is currently understood as approximate performances based on interpretations and perceived expectations, which are conditioned within the multiple contexts, subject positions, and materials conditions surrounding specific literacy events. (Shroeder 2004, p. 61).

In short, writers negotiate multiple, fluid subject positions and identities, multiple genres, multiple rhetorical situations, and multiple audiences as they invent and craft discourse. Students need to learn how to work in a "liquid network," to use Johnson's term, and how to move among nodes and the relations they are forging among nodes to create knowledge. We need to get them to understand invention not as a flash, or as something brand-new and never thought of before, but as reconfiguring relations among the nodes, and writing as contributing to ongoing, fluid conversations. 
I'm not recommending a set of static approaches to invention, but rather a vision of creation or invention that is especially robust and that will challenge us to help students create strategies for negotiating these practices. What, now, does a new invention look like-this new Inventio? Putting the pieces together, I offer invention as the practice of creating a web or network of situated nodes-embodied practices that create sets of relations among the writer and her world, the writer and her time, the writer's self and others, the writer's self and supracollectives, and the writer's discourses among varying ongoing discourses. We need to get students to understand that discourses swirl around in a three-dimensional space, as the writer moves among the varying nodes and back again, and onward and back, and so forth. The discourse created gets placed within the other discourses that have been created, and is itself not a stable, coherent, static entity. Every time this discourse is picked up from within the stack or clicked on with a digital space, it offers a new reading. Invention then is a force, a moving forward and folding back on itself-a series of 'Circulations, runs, transfers, translations, displacements, crystallizations.'

If we are to teach students not just to "consume knowledge" and "demonstrate knowledge" (those instances where students give answers to questions already known), but rather to "create knowledge" and "make meaning" that will serve them in a variety of academic, public, civic, and private spaces and situations and other places they traverse, then we need a robust theory of invention. One that doesn't see invention as a process that takes place in the beginning of a project, but one that happens throughout in the drafting, circulating, reading, and remixing-one that is never ending. We need to rethink our processgenerated collection of invention strategies-brainstorming, free writing and focused free writing, journaling, outlining, for example-that are typically taught to students regardless of the text they are to craft, or their rhetorical situation for the text, or their own writer's stance. I'm not suggesting that these strategies are in themselves necessarily bad strategies; but they all focus inward, and assume a knowledge that is already known. Such strategies encourage consumption and demonstration of knowledge, rather than invention and meaning making

By contrast, we need to teach our students rhetorical theory and praxis, so that they understand the nodes they already traverse, and the relations they build among the nodes. We need to get them to understand that all discourse-oral, written, and digital-works in this way. We then need to teach students how to build relations among all sorts of aspects of the discursive-bodily-material-temporal nodes, in various discourse genres. In the different intersections-where meaning making takes place in the spaces between-students need to learn how to pose lots of questions, as they consider the world, themselves, other people, supracollectives, and other discourses; they need to learn how to consider the relations they are building among the nodes. Students should be taught how to pose questions themselves, so that they can create the heuristics that are useful to them as they explore various genres in various social spaces. We need, that is, to help students create a curious mind that is determined to follow through, and we need to provide an environment (whether in class, hybrid, or online) that both encourages and fosters active curiosity.

I offer this model as one way to think about SoTL, teaching, and invention, and I invite others to participate in (re) inventing inventio. 


\begin{abstract}
Note
' Kelly Pender (2011) articulates the multiple definitions of the term téchne, classifying them into five composite definitions. " 1 . Techne as a 'how-to' guide or handbook; 2 . Techne as a rational ability to effect a useful result; 3 . Techne as a means of inventing new social possibilities; 4. Techne as a means of producing resources; 5. Techne as a non-instrumental mode of bringing forth" (p. 16). Janet Atwill (1998) and Janet Atwill and Janice Lauer (1995) draw on a concept of téchne to argue for rhetoric as a productive, inventional form of knowledge and knowledge making, as opposed to the more common position of rhetoric as hermeneutical form of knowledge and knowledge making.
\end{abstract}

\title{
References
}

Atwill, J. (1998). Rhetoric reclaimed: Aristotle and the liberal arts tradition. Ithaca, NY: Cornell University Press.

Atwill, J. \& Lauer, J. (1995). "Refiguring rhetoric as an art: Aristotle's concept of techne." In R. J. Gabin (Ed.), Discourse studies in honor of James L. Kinneavy (25-40). Potomac, MD: Scripta Humanistica.

Bell, A. (2005). "Bioart in question: Adam Zaretsky talks with Shannon Bell, Sam Bower, Dmitry Bulatov, George Gessert, Kathy High, Ellen K. Levy, Oron Catts \& I onat Zurrand and Jennifer Willet." CIAC's Electronic Magazine, 23. Retrieved from http://magazine.ciac.ca/archives/no 23/en/entrevue.htm

Clark, I. (2005). “Entering the conversation: Graduate thesis proposals as genre." Profession 2005 (141-52). New York: MLA.

Dees, D. M. (2008). A reflection on the scholarship of teaching and learning as democratic practice. International Journal for the Scholarship of Teaching and Learning, 2(2). Retrieved from http://academics.georgiasouthern.ed u/ijsotl/v2n2/personal_reflections/PD Fs/Reflection_Dees.pdf

Deleuze, G. \& Guattari, F. (2008). A thousand plateaus: Capitalism and Schizophrenia. London: Continuum.
Haraway, D. J. (1991). Simians, cyborg and women: The reinvention of nature. New York: Routledge.

Hawhee, D. (2002). "Kairotic Encounters." In J. M. Atwill, and J. M. Lauer (Eds.), Perspectives on rhetorical invention (pp. 16-30). Knoxville: University of Tennessee Press.

Hayles, N. K. (1999). How we became posthuman: Virtual bodies in cybernetics, literature, and informatics. Chicago: University of Chicago Press.

Johnson, S. (2010). "Where good ideas come from." TEDTalks. Retrieved from http://www. youtube.com/watch?v=0 af00UcTO-c\&feature=channel.

Kaufer, D. S., \& Geisler, C. (1989). "Novelty in academic writing." Written Communication 6, 286-311.

Keller, C. (2004). "Unsituating the subject: 'Locating' composition and ethnography in mobile worlds." In S. G. Brown, and S.I. Dobrin, (Eds.), Ethnography unbound: From theory shock to critical praxis (pp. 201-18). Albany: SUNY

Latour, B. (2000). "The Berlin key or how to do words with things." In $P$. M. Graves-Brown (Ed.), Matter, materiality, and modern culture ( $\mathrm{pp}$. 20-32). London: Routledge. 
Latour, B. (2005). Reassembling the social: An introduction to actornetwork theory. New York: Oxford University Press.

LeFevre, K. (1987). Invention as a social act. Carbondale: Southern Illinois University Press.

Liu, Y. (2002). "Invention and inventiveness: A postmodern redaction." In J.M. Atwill, and J.M. Lauer (Eds.), Perspectives on rhetorical invention (pp. 53-63). Knoxville: University of Tennessee Press.

Pender, K. (2011). Techne from neoclassicism to postmodernism: Understanding writing as a useful, teachable art. Anderson, SC: Parlor Press.

Prosser, M. (2008). The scholarship of teaching and learning: What is it?
A personal view. International Journal for the Scholarship of Teaching and Learning, 2(2). Retrieved from

http://academics.georgiasouthern.ed u/ijsotl/v2n2/invited_essays/PDFs/In vited $\% 20$ Essay Prosser.pdf

Shroeder, C. (2004). "The ethnographic experience of postmodern literacies." In S. G. Brown, and S.I. Dobrin, (Eds.), Ethnography unbound: From theory shock to critical praxis (pp. 53-72). Albany: SUNY.

Trigwell, K., \& Shale, S. (2004). Student learning and the scholarship of university teaching. Studies in Higher Education, 29(4), 523-36.

Young, R. \& Liu. (1994). "Introduction." Landmark essays on rhetorical invention in writing ( $p p$. xixxiii). Davis, CA: Hermagoras Press

Maureen Daly Goggin is Professor of Rhetoric and Chair of the Department of English at Arizona State University, where she manages up to 300 teachers at all ranks in a department that serves upwards of 16,000 students per semester. She is author of Authoring a Discipline (Erlbaum, 2000) and co-author of the Norton Field Guide to Writing with Readings (Norton, 2006; 2010); editor of Inventing a Discipline (NCTE, 2000); co-editor with Neal A. Lester of Racialized Politics of Desire in Personal Ads (Rowman and Littlefield, 2008); co-editor with Beth Fowkes Tobin of Women and Things, 1750-1950 (Ashgate, 2009), Women and the Material Culture of Needlework and Textiles, 1750-1950 (Ashgate 2009), and Material Women, 1750-1950 (Ashgate, 2009). With Tobin, she has two more books forthcoming from Ashgate, The Materiality of Color and Women and the Material Culture of Death. She has written extensively about the history and field of rhetoric, gender and race, and visual and material culture. 